\title{
Quantitative Analysis of Eye Movements during Singing of Early Childhood Children
}

\section{Mina Sano}

Department of Education and Care of Early Childhood, Faculty of Education and Care of Early Childhood, Tokoha University, Shizuoka, Japan

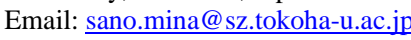

\author{
Article History \\ Received: 26 June, 2021 \\ Revised: 9 August, 2021 \\ Accepted: 28 August, 2021 \\ Published: 2 September, 2021 \\ Copyright (C) 2021 ARPG \& \\ Author \\ This work is licensed under the \\ Creative Commons Attribution \\ International \\ (ㄷ) (1) CC BY: Creative \\ Commons Attribution License \\ 4.0
}

\begin{abstract}
Early childhood children tend to make musical expressions watching other children or the teacher's piano accompaniment. However, it has not been inspected yet how eye movement is affected by music. To provide the optimized procedure to capture eye movement's characteristics reflecting music, the statistical technique was used to evaluate effective parameters. In this study, eye trackers (Tobii Glasses 2) were used to acquire data of eye movements during musical expression of early childhood children and to conduct quantitative analysis. 3-year-old, 4-year-old, and 5year-old children in two early childhood facilities $(n=58)$ participated in eye-tracking while singing multiple songs of major and minor. This paper focuses on saccade (rapid eye movement) and gaze behaviors of early childhood children and mainly conducts, a three-way analysis of variance (ANOVA) on the acquired data (age * facility*tonality). As a result, it was found that the number of occurrences of saccade and the total moving distances of saccade showed a statistical significance between means regarding differences in the tonality of major/minor key of songs, and childcare forms.
\end{abstract}

Keywords: Eye movement; Saccade; Early childhood development; A three-way ANOVA; Tonality of major / minor.

\section{Introduction}

Regarding relationship of eye movement and body control, evidence from previous studies suggests that saccade and gaze behavior infer body position and postural control (Neil et al., 2016). However those studies are targeting only adults and not including music induced responsive body movements.

The author has been interested in evolution of musical expression of children influenced by music education. For four years, the author has quantified changes of body movements included in musical expressions utilizing 3D motion capture (XSENSE MVN system) during the practical process of musical expressions in order to evaluate development of the musical expressions in early childhood. Generally, currently available research reports that use 3D motion capture in the field of education show consideration of the results of specific motion analysis of traditional Japanese dance and sawing, mainly for adults, and development of learning support methods (Ando and Sumikawa, 2012; Sato et al., 2010). Researches on music and movement show responses to adult sound (Burger, 2013), viewing experiments and video analysis on the relationship between performer movements and expressions (Dahl and Friberg, 2007; Thompson and Luck, 2012). Those researches did not aim to capture the musical expressions during the process of continuous musical practice in early childhood.

In order to give clear vision of relationship between music and induced body movements, the author have conducted machine learning by using the motion capture data acquired in 2016 as the baseline training data, and performed varieties of classification model on the acquired data from 2017 to 2019 to predict the developmental degree of musical expression in early childhood. Machine learnings are well introduced in educational fields such as behavior recognition and individual recognition methods in daily life (Kodama et al., 2015; Takada et al., 2012), inspection of eye movement patterns of an elementary school children regarding arithmetic education (MorenoEstevaa et al., 2019), and motor learning support such as upturning of elementary school students (Matumoto et al., 2014). Though, there have been no reports of research using machine learning regarding musical expression in early childhood. The author found effective feature quantities derived from body movement dynamics which supports to enhance classification accuracy of developmental characteristics of musical expression in early childhood. By using a specific machine learning method (Fernandez-Delgado et al., 2014), the author devised a method to evaluate the developmental process of musical expression in three stages (Sano, 2019;2020).

It is necessary to capture three-dimensionally and quantitatively analyze not only body movement but also eye movement during musical expression to clarify developmental degree of musical expression using machine learning 
technique. Because, early childhood children often make a musical expression such as singing a song while watching around other children's behaviors each other at the same time watching a teacher's piano accompaniment. The children think how express their own recognition of music elements by acquiring a visual information using their eye movements and take their action as musical expression.

Currently, what the participant child actually sees, feels, and thinks about is not still clear, except for the part that can be inferred from the observation of the participant child. In order to better understand the relationship between music and body movement interlink, the author focused on the eye movements during musical expression in early childhood, and tried to quantitatively analyze with eye tracking device.

Researchers previously have mainly used eye tracker of display system as a device that captures in two dimentions; (Higuchi et al., 2019; Kusunoki et al., 2017; Mpofu, 2016), and prediction of eye movement by reading pattern detection (Rajendran, 2018), and textbooks. Those researches also showed the results of analysis of eye movements and cognitive load in elementary school students (Seong-un et al., 2016), analysis of eye movements when reading picture books (Watabe et al., 2019), a relationship between infant cognitive function and eye contact (Urakawa et al., 2011), a relationship between the moving distance by the line of sight to the stimulus and the judgment of preference (Kouroki et al., 2016), and the movement of the line of sight in the joint attention scene (Hakuno and Minagawa, 2017; Nagai et al., 2017). In the music field, some researchers showed the results regarding auditory rhythm, eye movement during reading the sheet music (Fusase, 2017; Lörch et al., 2017; Plöchl and Obleser, 2017), and eye-hand synchronization during musical instrument performance (Marandola, 2017). Regarding music reading, an inspection of differences of eye movements reading and listening melodies between music experts and non-experts was showed (Drai-Zerbib and Baccino, 2018). Those researches have mainly sought to capture how music is perceived by eye movements. Burger et al. (2018) presented a synchronizing method using mobile eye-tracking with motion capture to make adulthood participants easier to move (Fink et al., 2019). In this way, even in research in the field of music, eye movements during musical expression in early childhood have not been taken as the subject of research.

The author tried to capture in three dimensions and quantitatively analyze eye movements during musical expression in early childhood by using eye tracker as wearable system because of extracting an effective feature quantity for the developmental process of musical expression. The eye movements dynamics captured by the eye tracker are saccade (rapid eye movement) information. Such movement of the eyeball can be quantified mainly by the moving speed (angular velocity) and the moving distance (magnitude of the angle). In this study, the author focused on derived values from data of saccades during musical expression for the purpose of explaining effective relationship between eye movement and musical expression.

\section{Purpose of This Study}

This study aims to use an eye tracker to quantitatively capture eye movements during musical expression in early childhood children. The author tried to quantitatively analyze whether or not there is a difference in eye movements depending on variety of conditions such as the tonality (major and minor) of songs in early childhood.

\section{Method of This Study}

The method of this study is to quantitatively capture the saccade when a child singing a song, and the following steps are showed.

\subsection{Eye Tracking Experiments During Singing A Song by Early Childhood Children}

Children in early childhood are singing songs while watching the accompaniment of teachers in nursery schools and the children around them. The author confirmed it by video analysis when observing the behavior of children, but could not quantitatively grasp how the actual eye movements were. Therefore, in this study, the author inspected using an eye tracker (Tobii Pro glasses 2) to focus and quantify the eye movements of early childhood children during singing a song.

Tobii Pro glasses 2 is a glasses-type eye tracker composed of one scene camera and four eye cameras with remotely wired connection to data recorders. The glasses weight 45 gramms and capture wide angle, which enable natural viewing behavior by children. Each participant child puts on it in the same way as glasses, calibrates it with a strap fixed, starts singing with a signal. The participant child was measured by eye-tracking system until the end of singing. It is a $1 / 50$ second time frame at $50 \mathrm{~Hz}$, and audio and video are recorded at the same time. Tobii Pro Lab with I-VT fixation filter (30 degrees/ second) was utilized to identify saccade characteristics. In this study, the children in the two nursery schools experience in their musical expression every day, and each participant sang one song in major key and another one in minor key. At U nursery school, the song in major key was "Umi" (G major, Japanese lyrics: Ryuha Hayashi, composition: Takeshi Inoue), and the song in minor key was "Ureshii HinaMatsuri" (A minor, Japanese lyrics: Sato Hachiro, composition: Koyo Kawamura). At M children's facility, each participant sang the song in major key as "Kaeru no Uta" (C major, Japanese lyrics: Toshiaki Okamoto, composition: German folk song), and the song in minor key as "Teruterubozu" (A minor, Japanese lyrics: Asahara Kagamimura, composition: Shinpei Nakayama). The measurement and analysis time per person was 20 seconds for songs in major key and 20 seconds for songs in minor key. 


\subsection{Participant Children of Eye Tracking and the Survey Schedule}

3 -year-old, 4-year-old, and 5-year-old children in U nursery school $(\mathrm{n}=28)$ participated in eye tracking during singing from 9:30 to 11:00 on August 18 in 2020, and M facility children $(n=30)$ from 14:30 to 16:00 on August 19 in 2020. U nursery school used a play-centered childcare form, and the M facility followed the Montessori method.

\subsection{Quantitative Analysis of Acquired Data by Eye Tracking}

In this study, in order to inspect how the eyeball moved, rapid eye movements from one fixation-point to another fixation-point was mainly analyzed. The author quantitatively analyzed the number of saccades that occurred during the measurement time, the moving average of angular velocity, the average of moving distance (total angle), the moving average of angular velocity of the first saccde and the magnitude of the first saccade.

Regarding the average value of those data, it was inspected whether showed a statistically significant difference by facility (U nursery school, M facility), age (3-year-old, 4-year-old, 5-year-old) and tonality (major/ minor). ANOVA (a three-way non repeated two standards as child facilities, non-repeated three standards as ages) and nonrepeated two standards as tonality was used. Furthermore, a statistical difference by four songs was inspected by ANOVA (a two-way non repeated four standards as songs, non-repeated three standards as ages) regarding the total moving distance of saccade.

\section{Results}

In this paper, the author shows an example of individual calculated data of eye movement analyzed by analysis software (Tobii Pro analyzer), and quantitatively analyzes the data items presented by the method of this study.

\subsection{How Saccade (Rapid Eye Movement) Occurs}

Regarding the occurrence of saccade, the analysis results of "Umi" (major) and "Ureshii HinaMatsuri" (minor) at U nursery school, and "Kaeru no Uta" (major) and "Teru teru bozu" (minor) at M facility, an individual example is shown. The following photo captures the moment when a 3-year-old child (boy) moves his eyes on the 9th second of singing the "Ureshii Hinamaturi".

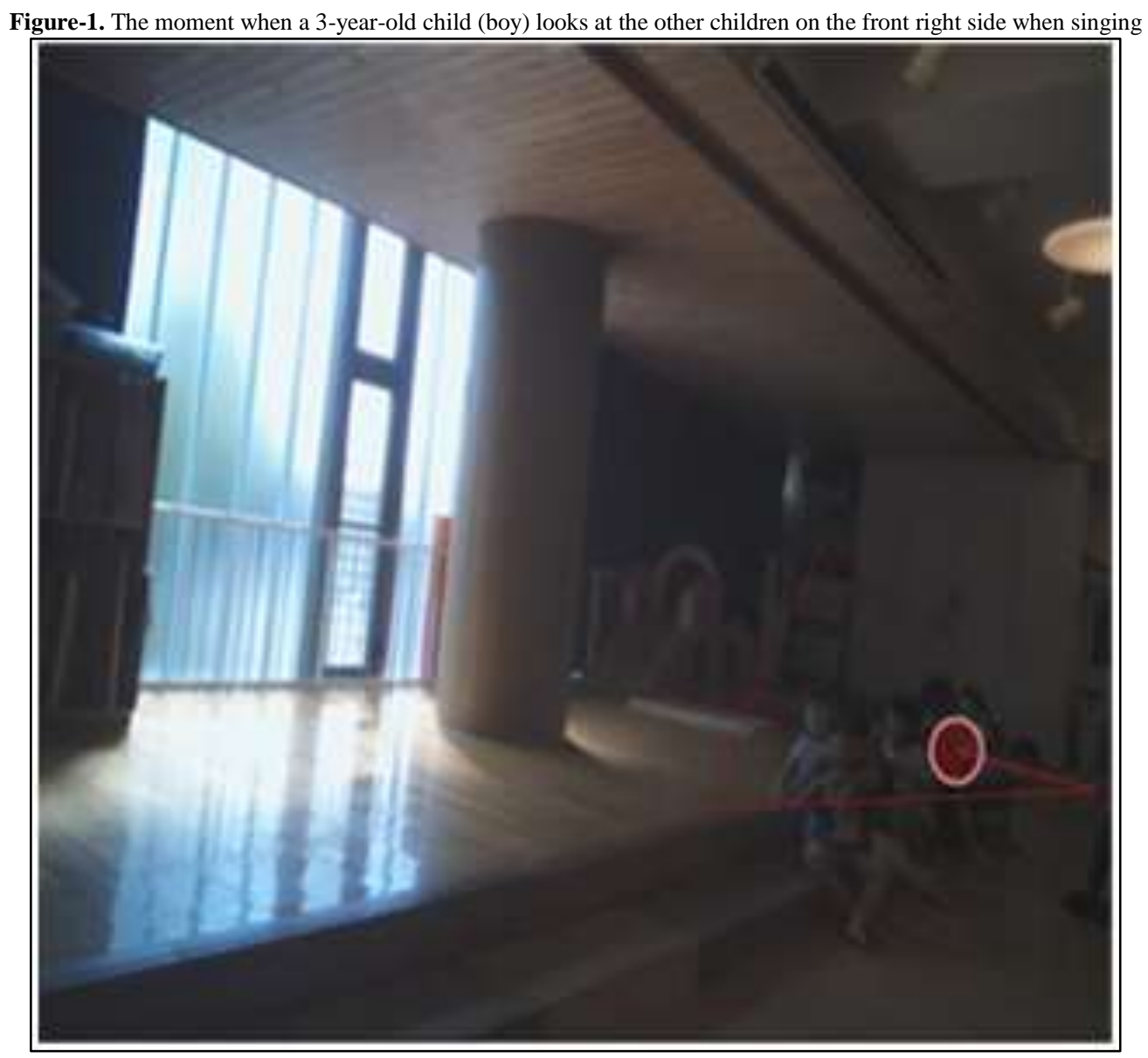

\subsection{The Moving Trace of The Line of Sight When Singing "Umi" (major)}

Figure 1.1 below shows the order of eye movements of a 3-year-old child (girl) when singing "Umi" (major), and Figure 1.2 shows the heat map. 
Figure-1.1. gaze plot when singing "Umi", a 3-year-old child (girl) in U nursery school

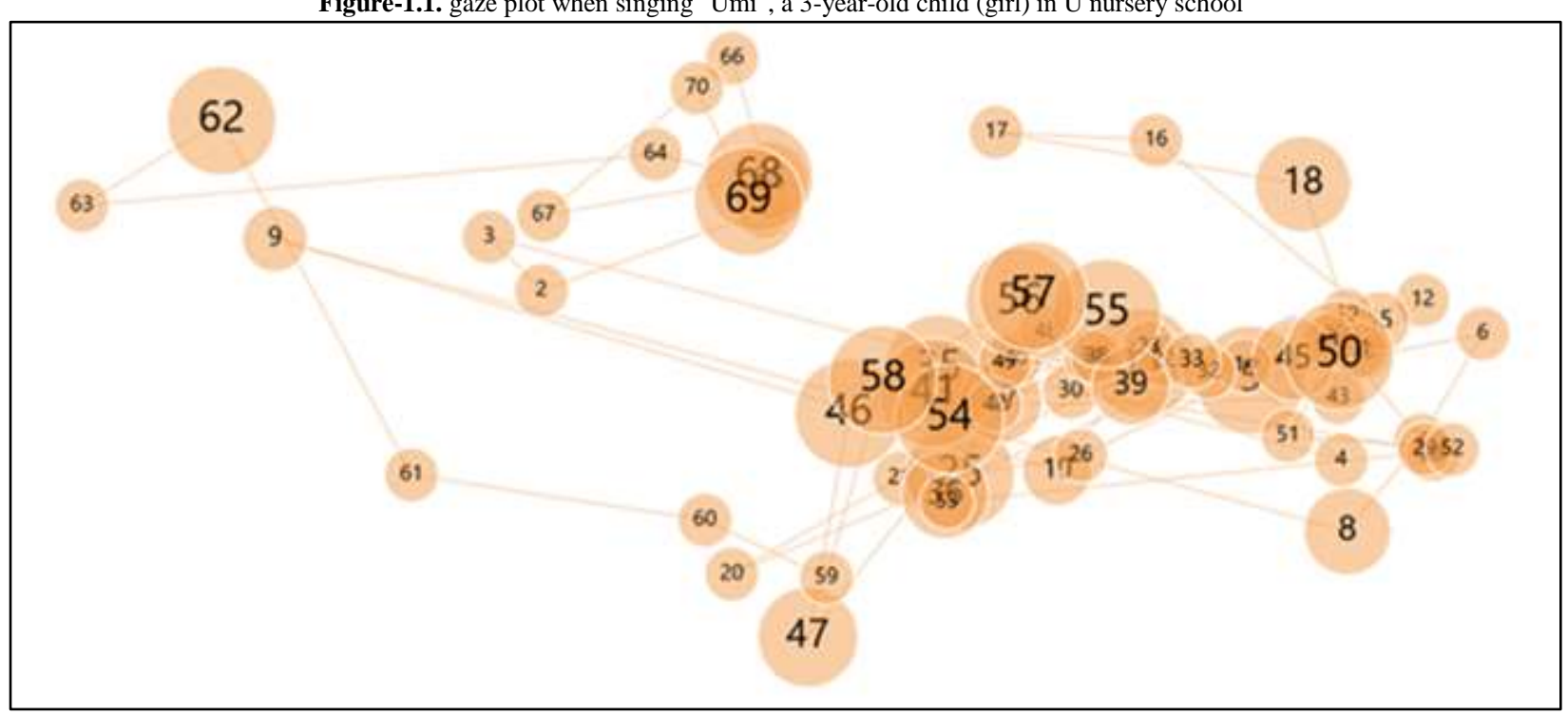

Figure-1.2. relative count (Fig.1-1. heat map of the number of line-of-sight movements)

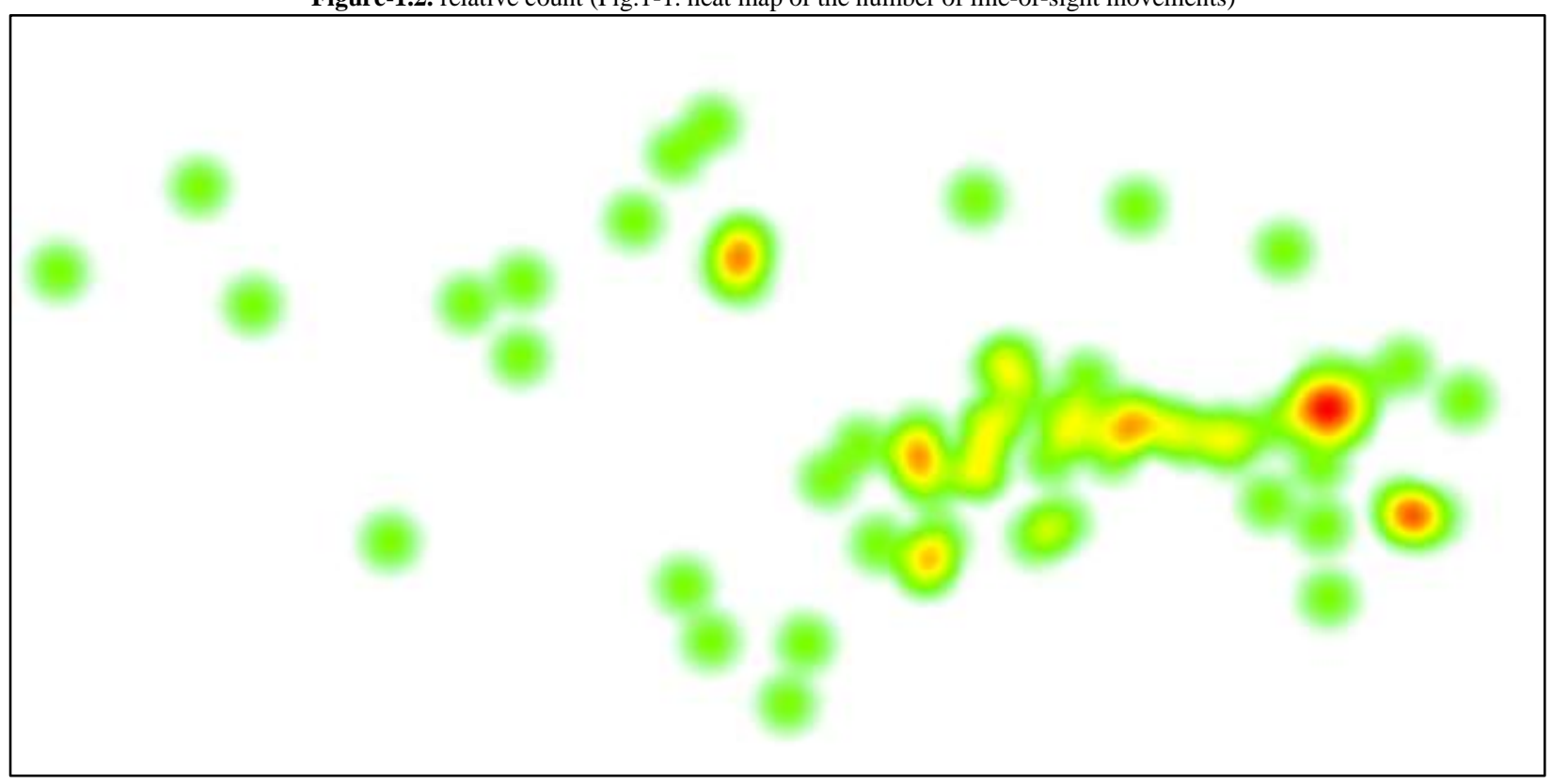

A piano accompaniment with his back turned to the front sits on the front left side of the participant child, and other children sat on the front right side. Some of the other children sang together, moved spontaneously, and took a beat. According to the video analysis shown in Fig. 1.1 and Fig. 1.2, the 3-year-old girl to be measured first looked at the other children, then looked at the piano accompaniment on the left side, and then saw the other children again. Singing while watching, she saw the piano accompaniment again at the end of the singing. In particular, the circles surrounding the numbers in each figure indicate that the time spent paying attention to them was relatively long, implying this participant child looked more closely at other children than with the piano accompaniment. Figure 1.2 shows a lot of eye movement on the right side where the other children are. Regarding "Umi", the movement of the line of sight during singing tended to follow a similar moving trace for 4-year-old and 5-year-old children.

\subsection{Movement of the Line of Sight When Singing "Ureshii Hinamatsuri" (minor)}

The following Figures 1.3 shows the order of eye movements of a 4-year-old child (boy) when singing "Ureshii Hinamatsuri" (minor), and Figure 1.4 shows the heat map. When singing "Ureshii Hinamatsuri", a piano accompaniment with his back turned to the front was sitting on the front left side of the participant child, and other children to be measured were sitting on the front right side, the same as environment when singing "Umi". According to Figures 1.3 and Figure 1.4 and the video analysis, the order of looking at the other children on the right side and the piano accompaniment on the left side was similar to that of "Umi". In the case of "Ureshii Hinamatsuri", the child sang while watching the piano accompaniment, and did not move as much to the left and right as when "Umi" was sung, but at the end of the singing, he watched the piano accompaniment for a long time. This tendency also occurred at other ages of participant children. 
Figure-1.3. U nursery school 4-year-old boy: gaze plot when singing "Ureshii Hinamaturi"

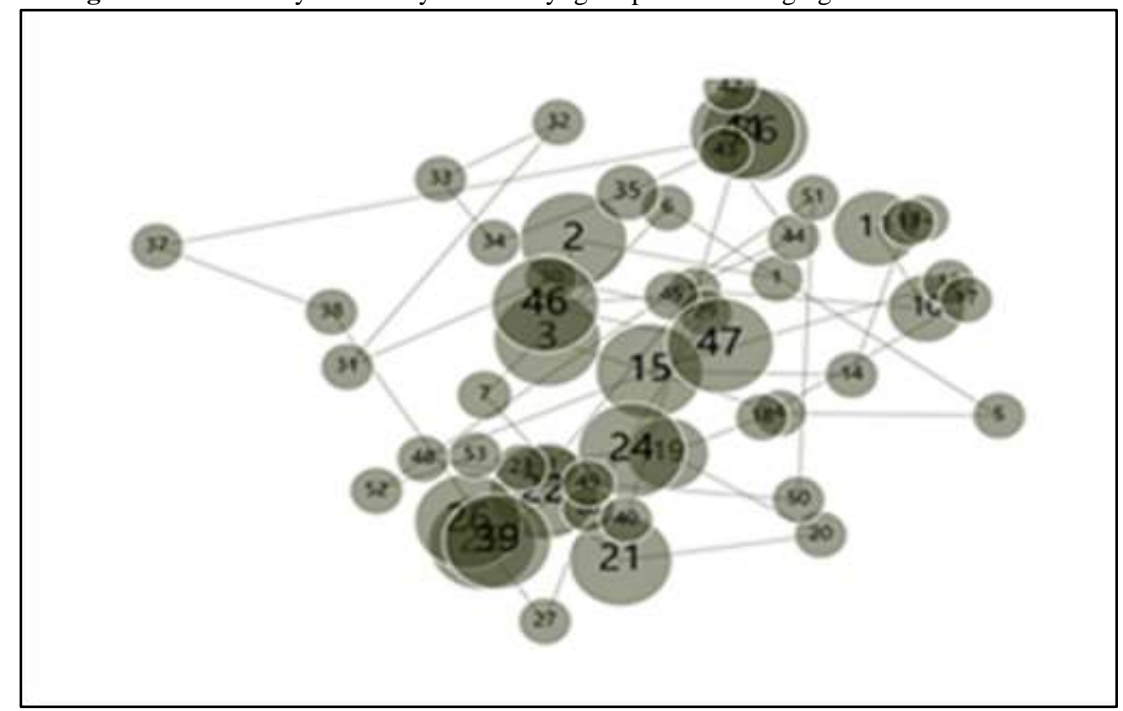

Fig-1.4. relative count (Fig. 1-3)heat map of the number of line-of-sight movements)

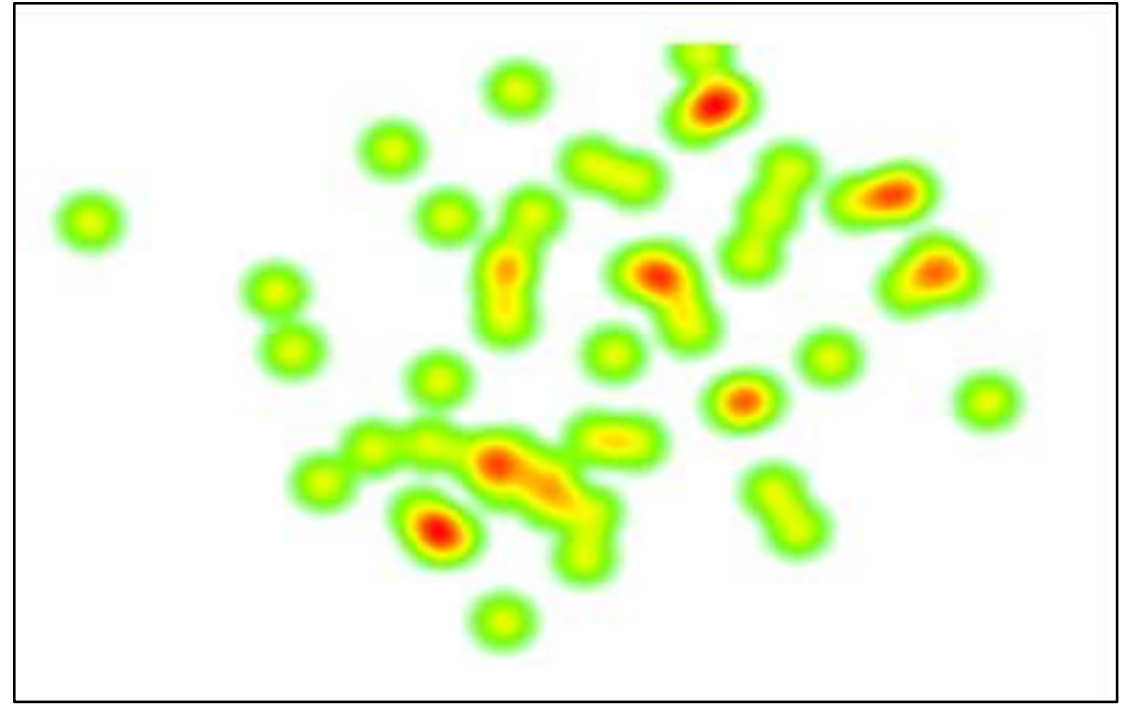

\subsection{Gaze Movement When Singing "Kaeru no Uta" (major)}

Figure 1.5 below shows the order of eye movements of a 3-year-old child (girl) when singing "Kaeru no Uta" (major). Figure 1.6 shows a 4-year-old child, and Figure 1.7 shows the order of movement. It shows the order of eye movements in a 5-year-old child.

Figure-1.5. M facility: 3-year-old child girl gaze plot when singing "Kaeru no Uta"

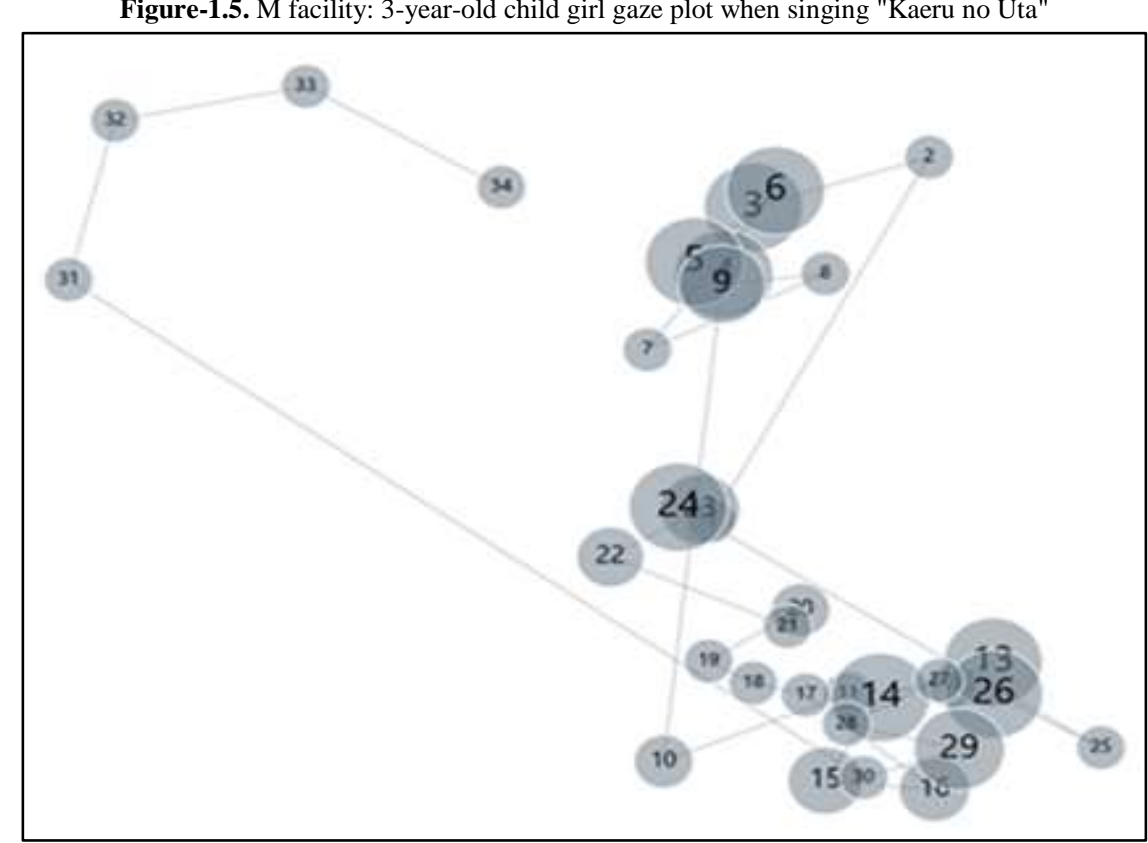


Figure-1.6. M facility: 4-year-old girl "Kaeru no Uta" gaze plot when singing

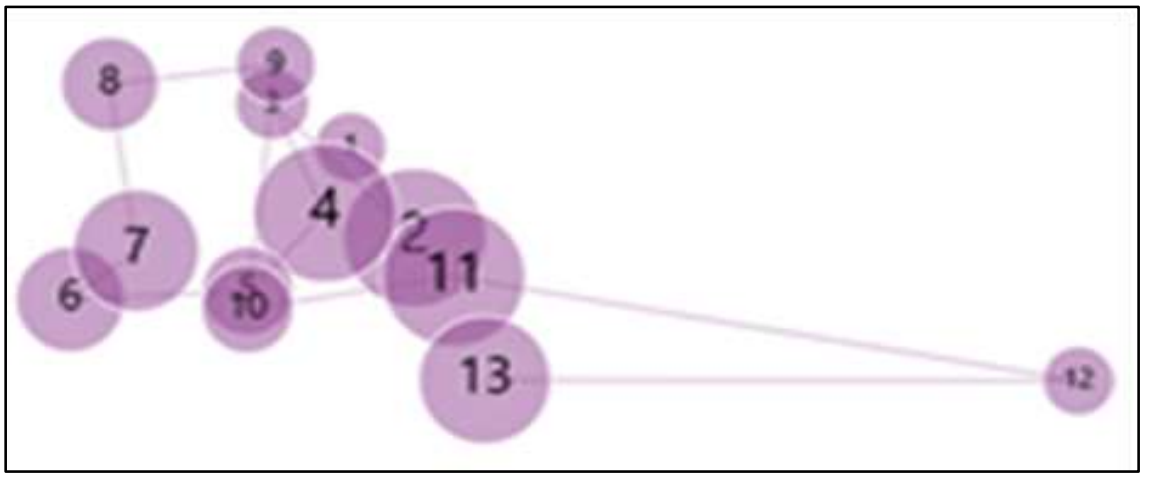

Figure-1.7. Gaze plot when singing "Kaeru no Uta", a 5-year-old girl in M facility

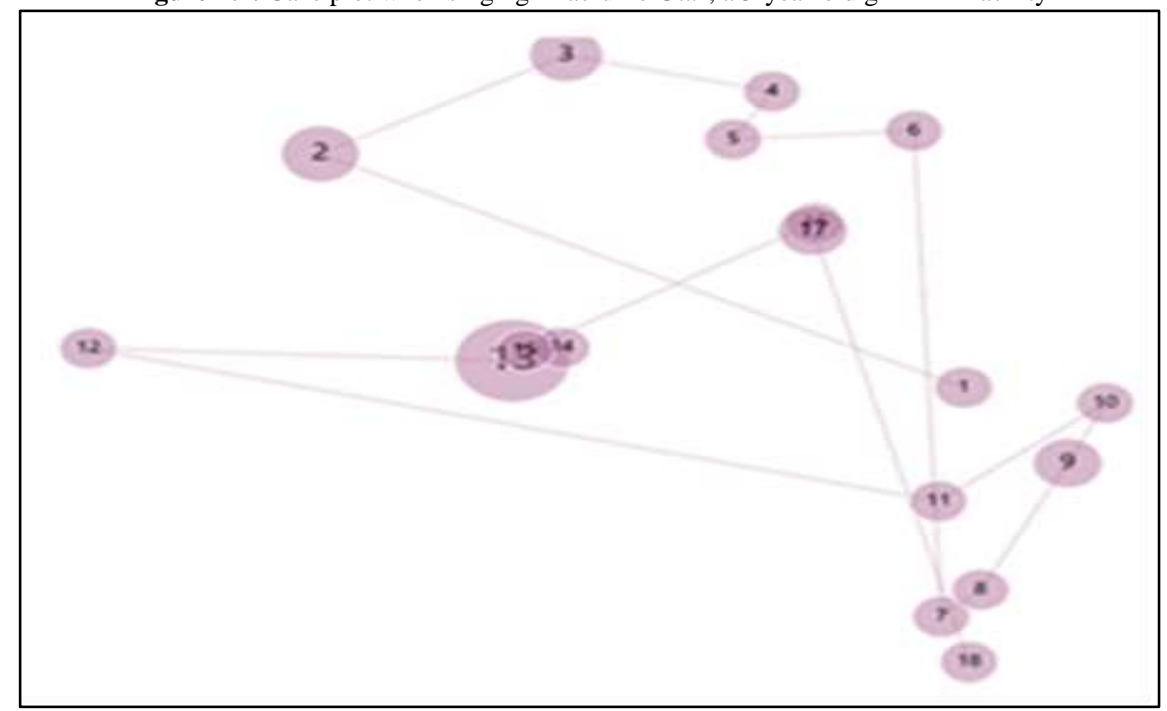

According to Fig. 1.5, Fig. 1.6, Fig. 1.7 and the video analysis results, the 3 -year-old child often looks at the other children on the right side, and sees the piano accompaniment only at the end of the singing. According to Fig. 1.6, the 4-year-old child does not have much eye movement, but she often sees the piano accompaniment. Figure 1.7 shows that in 5-year-old child, the line of sight shifts frequently, first looking at the other children, then the piano accompaniment, and then watching the piano accompaniment at the end of the singing.

\subsection{Movement of the Line of Sight When Singing "Teru Teru Bozu" (minor)}

Figure 1.8 below shows the order of eye movements of a 3-year-old child (girl) when singing "Teru teru Bozu" (minor). Figure 1.9 as 4-year-old child and figure 1.10 as 5-year-old show the order of eye movements.

Figure-1.8. Gaze plot when singing "Teru teru Bozu" singing "Teru teru Bozu" when a 3-year-old girl in M facility

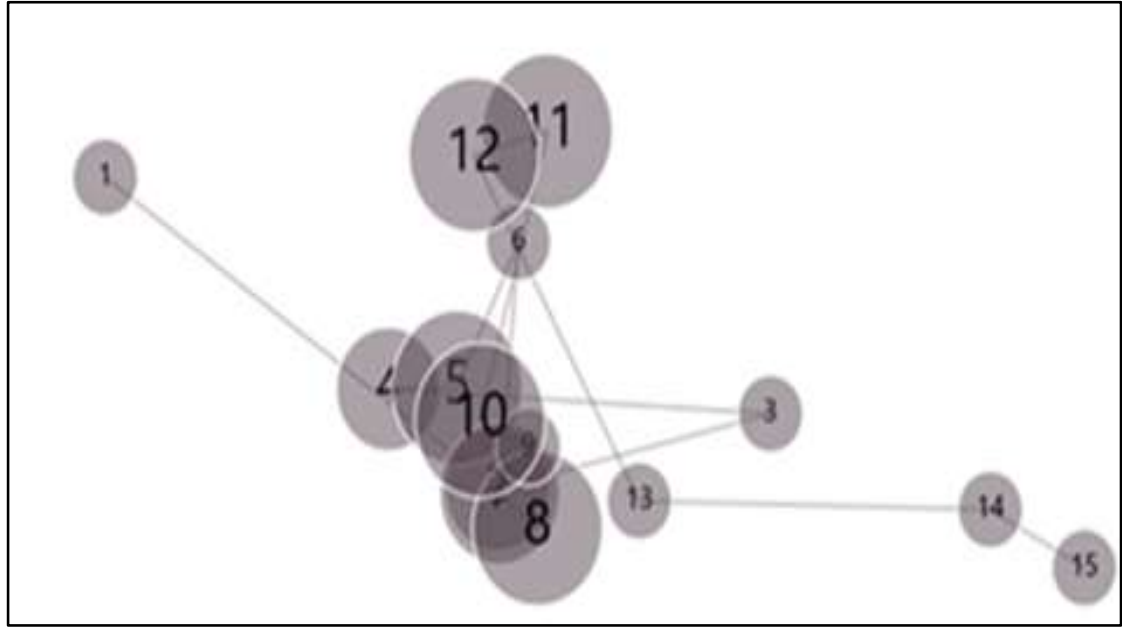


Figure-1.9. Gaze plot when a 4-year-old girl in M facility

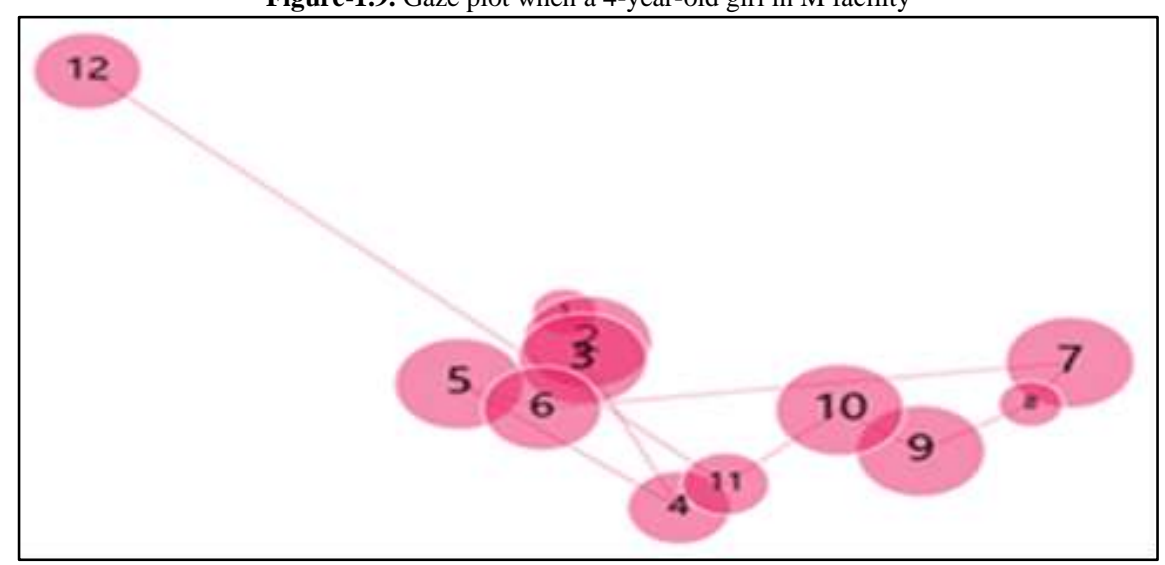

Figure-1.10. Gaze plot when singing "Teru teru Bozu" a 5-year-old girl in M facility

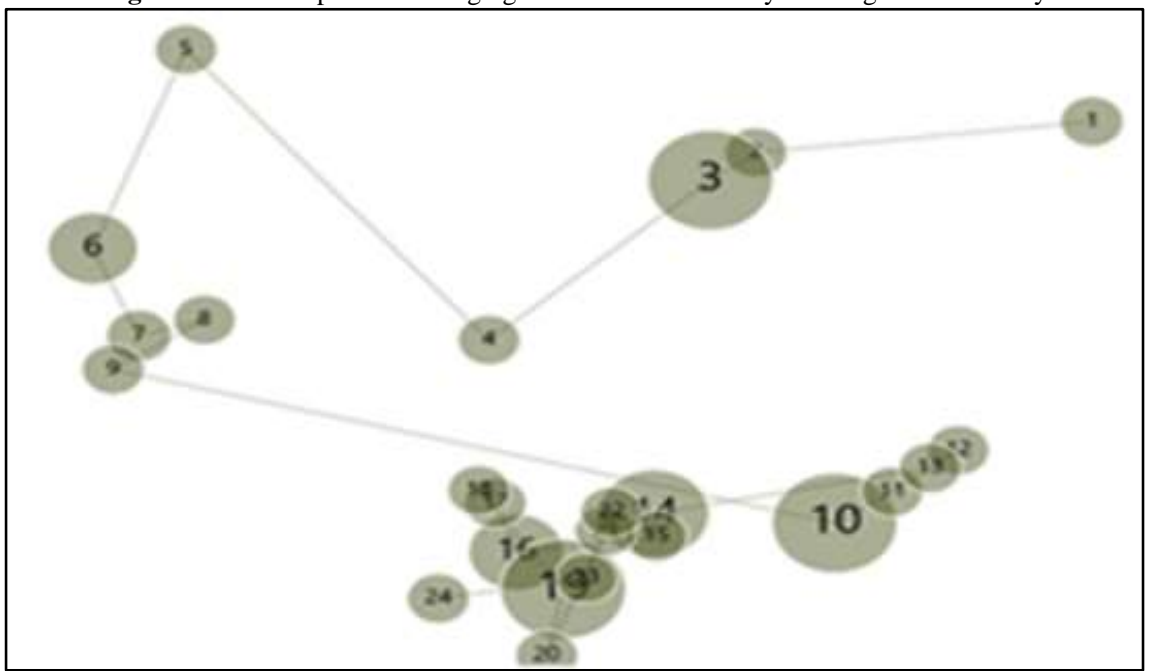

\subsection{Number of Saccades}

Table 2.1 below shows the average number of saccades during each measurement.

Table-2.1. The average number of saccades

\begin{tabular}{l|l|l|l|l|l}
\hline Child Facility & Age & Tonality & M & SD & N \\
\hline & 3-year-old & major & 19.875 & 9.26495 & 8 \\
\hline & & minor & 21.125 & 5.66789 & 8 \\
\hline U nursery & 4-year-old & major & 18 & 10.50926 & 10 \\
\hline school & & minor & 18.1 & 9.46866 & 10 \\
\hline & 5-year-old & major & 14.9 & 8.33267 & 10 \\
\hline & & minor & 24.2 & 12.14542 & 10 \\
\hline & 3-year-old & major & 14.7778 & 7.01388 & 9 \\
\hline M child facility & & minor & 4.8889 & 1.83333 & 9 \\
\hline & & major & 11.4444 & 9.22105 & 9 \\
\hline & 5-year-old & minor & 6.5556 & 4.50309 & 9 \\
\hline & & major & 16 & 6.45262 & 12 \\
\hline
\end{tabular}

A three-way ANOVA (non-repeated two standards as child facilities, non-repeated three standards as ages and nonrepeated two standards as tonality (major / minor)) was carried out to inspect whether a statistically significant difference was showed in the average value of the number of saccades in the participant children. As a result, a main effect / interaction of the test showed a statistically significant difference (child facility: $F(1,104)=37.185, p<.005$ ), child facility* tonality(major/ minor): $F(1,104)=13.782, p<.005)$. The test regarding simple main effect test with multiple comparisons was carried out by Bonferroni method.

Concerning the facility factor/ age factor * tonality factor, the simple main effect was statistically significant in 3 year-old $(F(1,104)=17.988, p<.005), 4$-year-old $(F(1,104)=10.171, p<.005)$ and 5-year-old $(F(1,104)=21.433$, $p<.005)$. As a result of multiple comparison, $\mathrm{U}$ nursery school was significantly larger than $\mathrm{M}$ facility in minor key for all 3-year-old, 4-year-old and 5-year-old children. In this way, statistically significant differences were not observed in the major songs but in the minor songs, and the number of saccades during each measurement of $U$ 
nursery school children was significantly larger than the number of saccades during each measurement of M facility children.

Figure 2.1 and Figure 2.2 show the average number of saccade occurrences at each measurement by facility and tonality (major/ minor).

Figure-2.1. Number of saccades in U nursery school

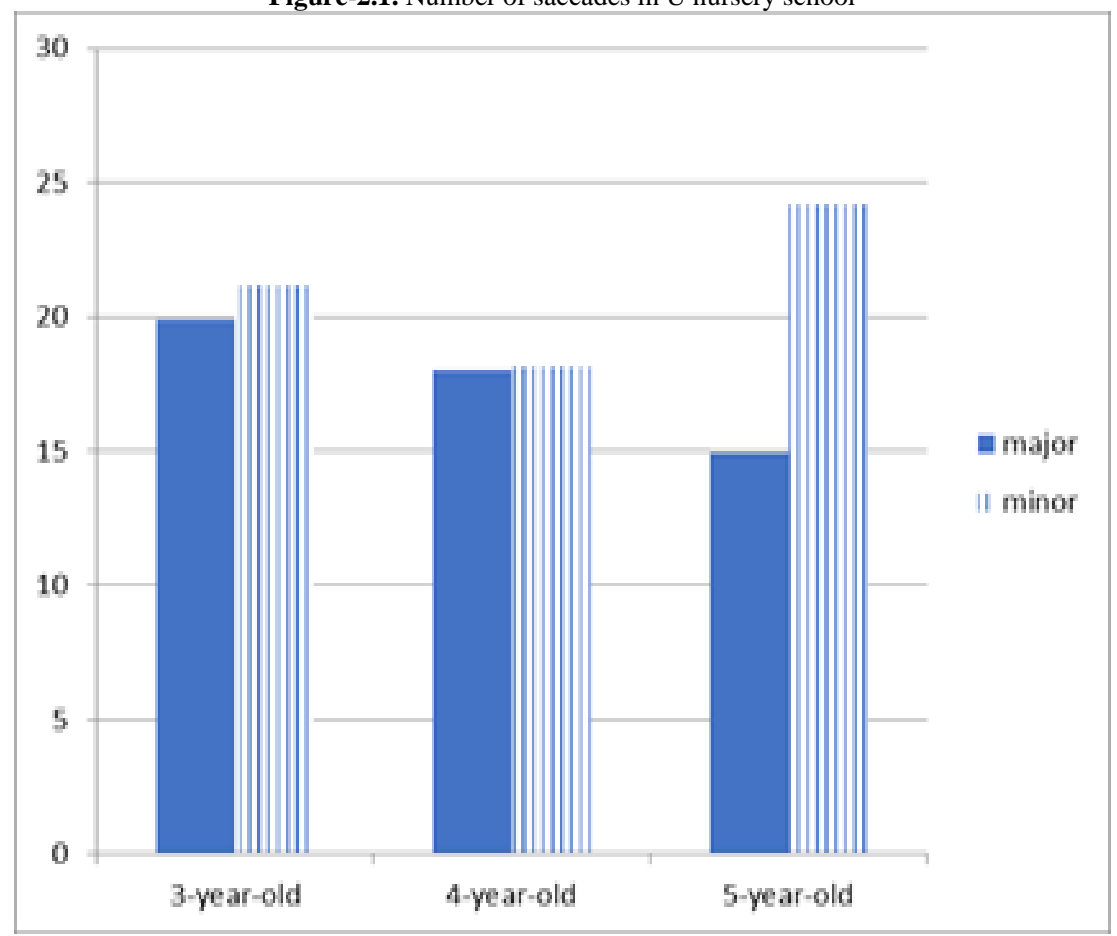

Figure-2.2. Number of saccades in M facility

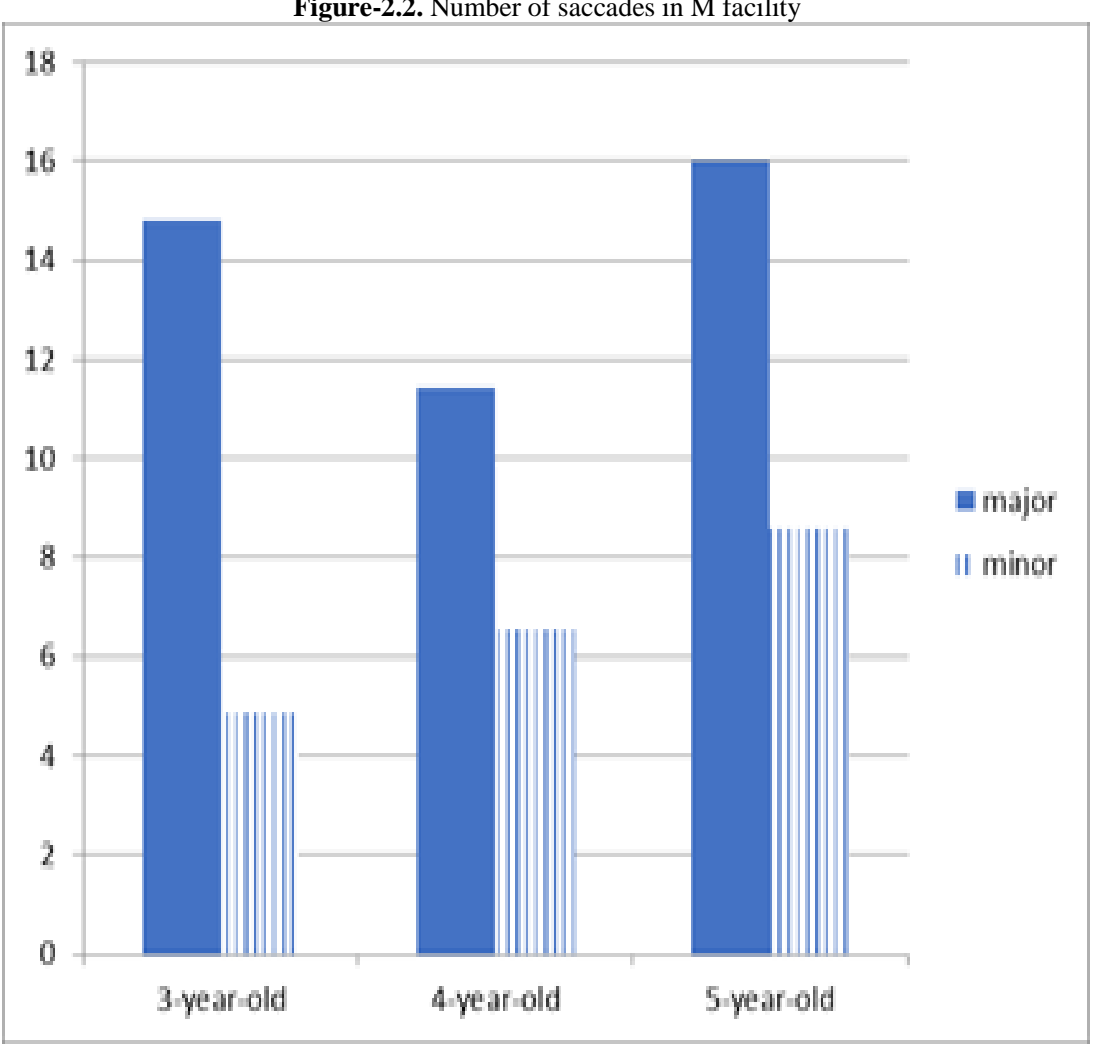

Figure 2.2 shows number of saccades in U nursery school. There is no statistically difference in the number of saccades of the major "Umi" and minor "Ureshii Hinamatsuri" between 3-year-old and 4-year-old children, but in 5year-old children, when singing a minor song, saccade indicates that the number of occurrences of is large. Figure 2.2 shows that saccades in M child facility when the children singing the song "Kaeru no Uta" in major key occur more than singing the song "Teru teru Bozu" in minor key. It shows that the frequency of occurrence in 3-year-old and 5-year-old children is characteristic.

Furthermore, a two-way ANOVA (non-repeated four standards as songs and non-repeated three standards as ages) was carried out to inspect if there was a statistically significant difference among songs. As a result of main 
effect / interaction of the test, a main effect showed a statistically significant difference (song: $F(3,104)=17.661$, $p<.005$ ). As a result of multiple comparisons, saccades occurred significantly more frequently in 3-year-old and 4year-old children in "Umi" and "Ureshii Hinamatsuri" than in "Teru teru Bozu". The frequency of saccades in 5year-olds was significantly higher in "Ureshii Hinamatsuri" than in "Teru teru Bozu".

\subsection{The Moving Average Velocity of Saccade (Angular Velocity)}

In the case of eye movements, the moving average velocity of rapid eye movements is expressed in angular velocity (angle / second). Similarly, a three-way ANOVA (non-repeated two standards as child facilities, non- repeated three standards as ages and non-repeated two standards as tonality (major / minor)) was carried out for this acquired data. A result of main effect/ interaction of the test did not show a significant difference, but the moving average velocity of saccade in 5-year-old children in $\mathrm{M}$ child facility was significantly larger than that in 3-year-old children in the minor song. The moving average velocity of saccades for 3-year-olds in $\mathrm{M}$ child facility was significantly larger in major songs than in minor songs. In the song "Teru teru Bozu" (minor), the moving average velocity of the saccade for 5-year-olds was larger than that for 3-year-olds.

Figures 3.1 and figure 3.2 show the moving average velocity by age group in major and minor.
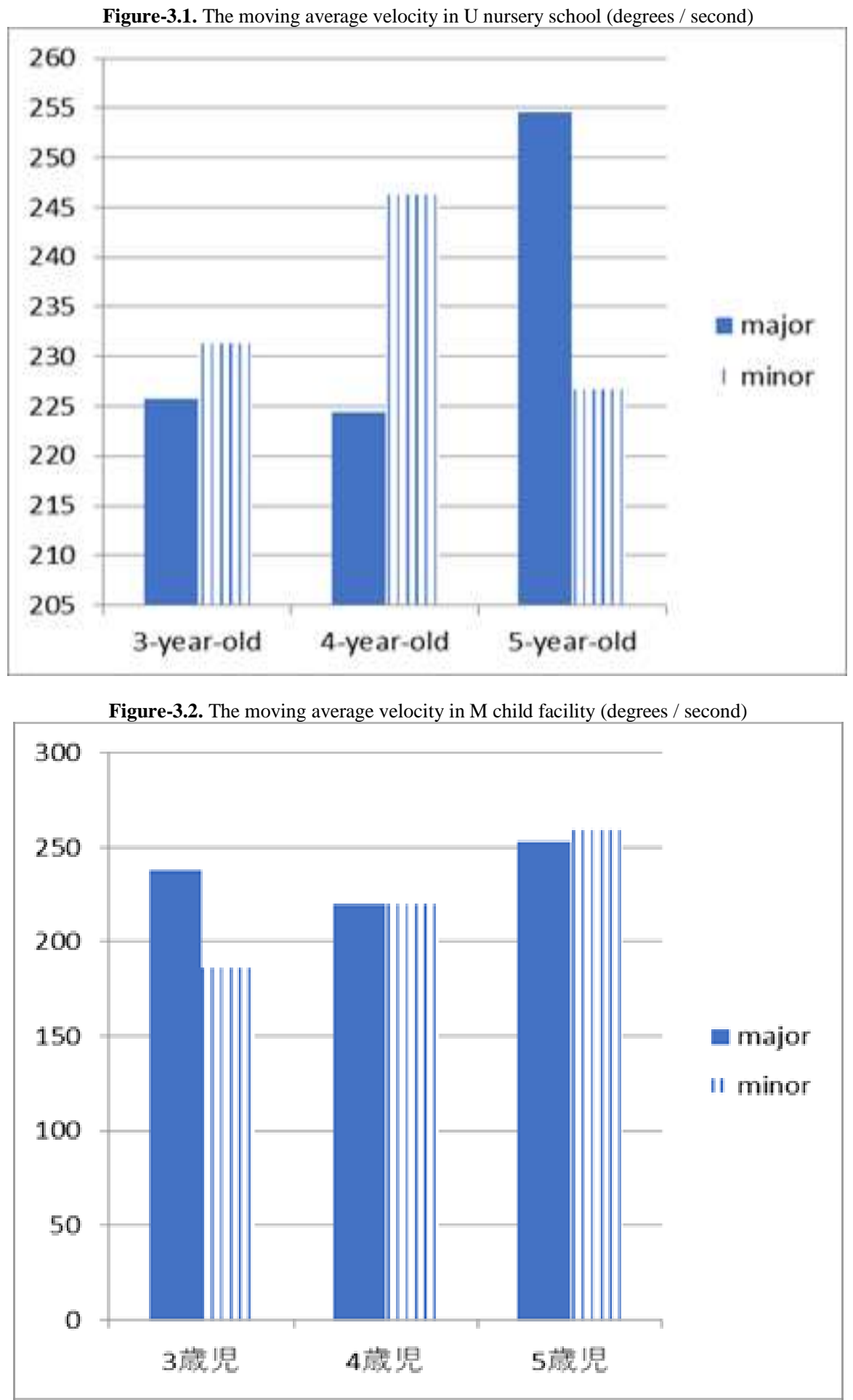
As shown in figure 3.1 in U nursery school, the moving average velocity (246.329 degree / second) when a 4 year-old child is singing a song in minor key was larger than the moving average velocity ( 224.392 degree / second) when singing a song in major key. For 5-year-olds, it was larger when singing a song in major key (254.645 degree / second). As shown in figure 3.2, regarding 3-year-old in $\mathrm{M}$ child facility, the moving average velocity (238.011degree/ second) when singing a song in major key was larger than the moving average velocity (186.3311degree / second) when singing a song in minor key although a significant difference between major key and minor key was little observed in 4-yer-old and 5-year-old.

Figure 3.3 below shows the changes in the moving average velocity of saccade depending on the song by ages.

Figure-3.3. The changes in saccade moving average velocity (degree / second) by ages

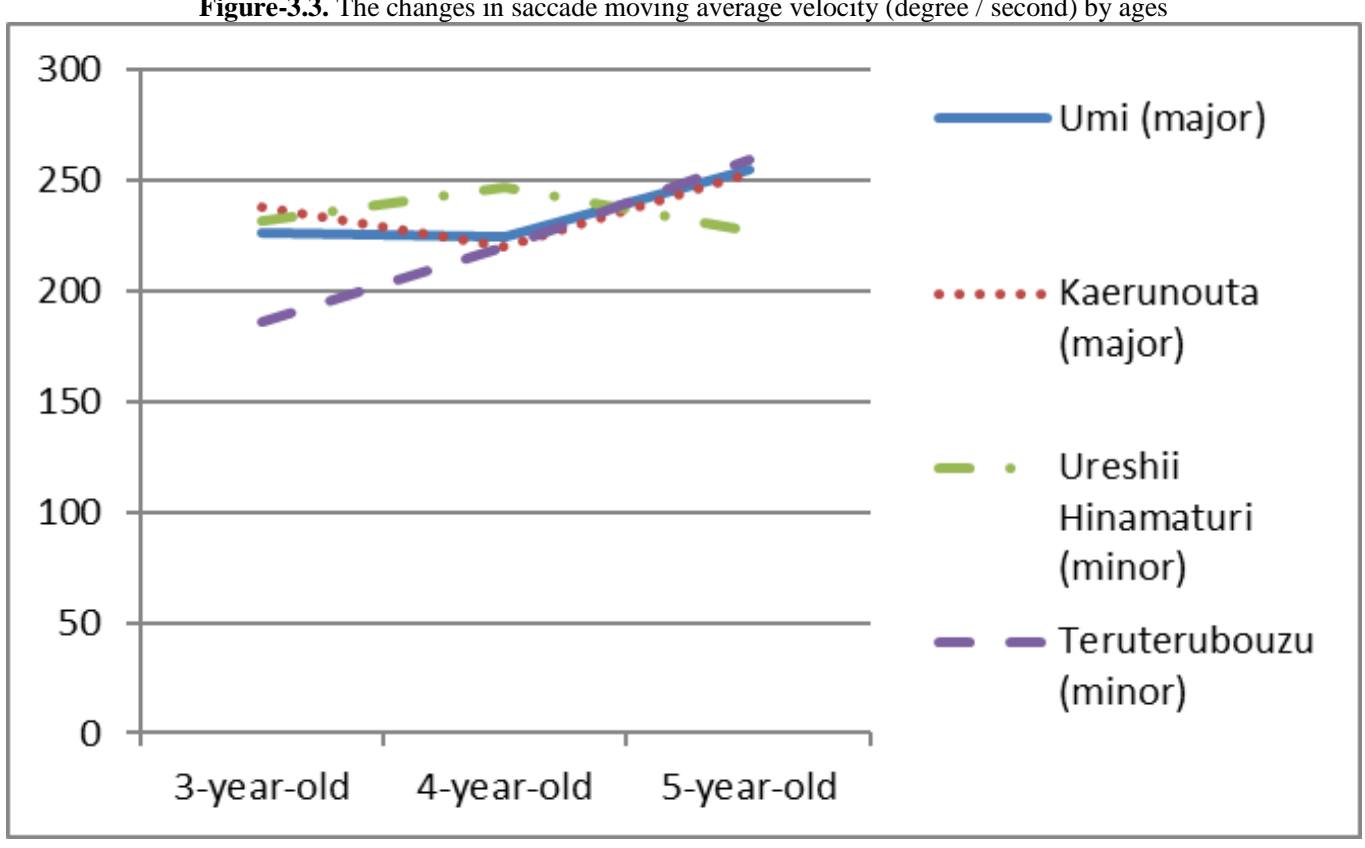

As shown in Fig. 3.3, there is not much change by age at the "Ureshii Hinamatsuri ", and at "Kaeru no Uta", "Umi", and " Teru teru Bozu", the moving average velocity increases as the age increases. In particular, in the song "Teru teru Bozu", change of 5-year-olds were larger than 3-year-olds and 4-year-olds.

\subsection{Average Data of Saccade}

Saccades have occurred many times, but the average values did not differ significantly. Figure 4 shows the average value of saccade by age for each song.

As shown in Figure 4, the average saccade of "Teru teru Bozu" by 5-year-old children was larger than that of 3 year-old and 4-year-old children.

Figure-4. Average value (angle) of saccade by age according to the song

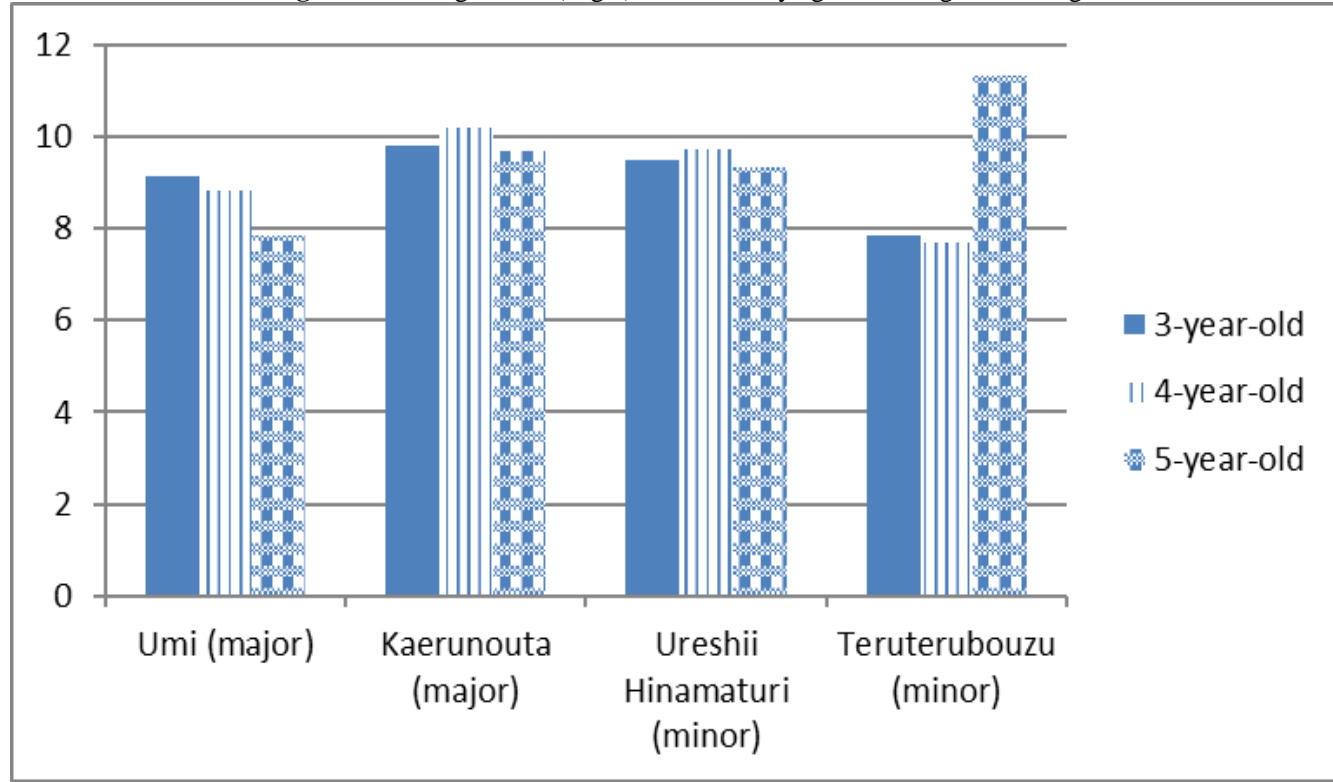




\subsection{Total Moving Distance of Saccade (Total Angle)}

In the case of saccade, the total moving distance is indicated by unit of angle.

Table 2.2 shows the average value of the moving distance each measurement.

Table-2.2. The average value of the moving distance of saccade (degree)

\begin{tabular}{l|l|l|l|l|l}
\hline Facility & Age & Tonality & Average & SD & N \\
\hline & 3-year-old & major & 177.3925 & 87.82232 & 8 \\
\hline & & minor & 204.5575 & 83.86732 & 8 \\
\hline U nursery school & 4-year-old & major & 166.643 & 106.036 & 10 \\
\hline & & minor & 175.55 & 106.5263 & 10 \\
\hline & 5-year-old & major & 126.014 & 84.17718 & 10 \\
\hline & & minor & 235.001 & 148.6135 & 10 \\
\hline & 3-year-old & major & 148.9222 & 99.34946 & 9 \\
\hline M child facility & & minor & 40.8122 & 30.54065 & 9 \\
\hline & 4-year-old & major & 121.7756 & 120.7692 & 9 \\
\hline & & minor & 55.8367 & 48.28457 & 9 \\
\hline & 5-year-old & major & 165.0575 & 96.21823 & 12 \\
\hline & & minor & 96.085 & 56.75702 & 12 \\
\hline
\end{tabular}

Concerning the result of a three-way ANOVA (non-repeated two standards as facilities, non-repeated three standards as ages and non-repeated two standards as tonalities(major/ minor)), a main effect/ interaction of the test showed a statistically significant difference (facility: $F(1,104)=18.53, p<.005$ ), facility* tonality (major/ minor): $F(1,104)=13.382, p<.005)$. The test regarding simple main effect with multiple comparisons was carried out by Bonferroni method.

Concerning the facility factor/ age factor * tonality factor, the simple main effect was statistically significant in 3 -year-old singing in minor key $(F(1,104)=12.725, p<.005)$ and 5-year-old singing in minor key $(F(1,104)=11.795$, $p<.005)$. As a result of multiple comparisons, the total moving distance of saccade regarding 3-year-old, 4-year-old and 5-year-old singing in minor key, $\mathrm{U}$ nursery school was significantly larger than $\mathrm{M}$ child facility. The average data of total moving distance of saccade when singing in minor key was larger than the average data singing in major key regarding 5-year-old in U nursery school. The average data of total moving distance of saccade when singing in major key was larger than the average data singing in minor key regarding 3 -year-old in $\mathrm{M}$ child facility at the measurement time.

The following figures 5.1 and figure 5.2 show the average value of the total moving distance of saccade by age in major and minor, by facility.

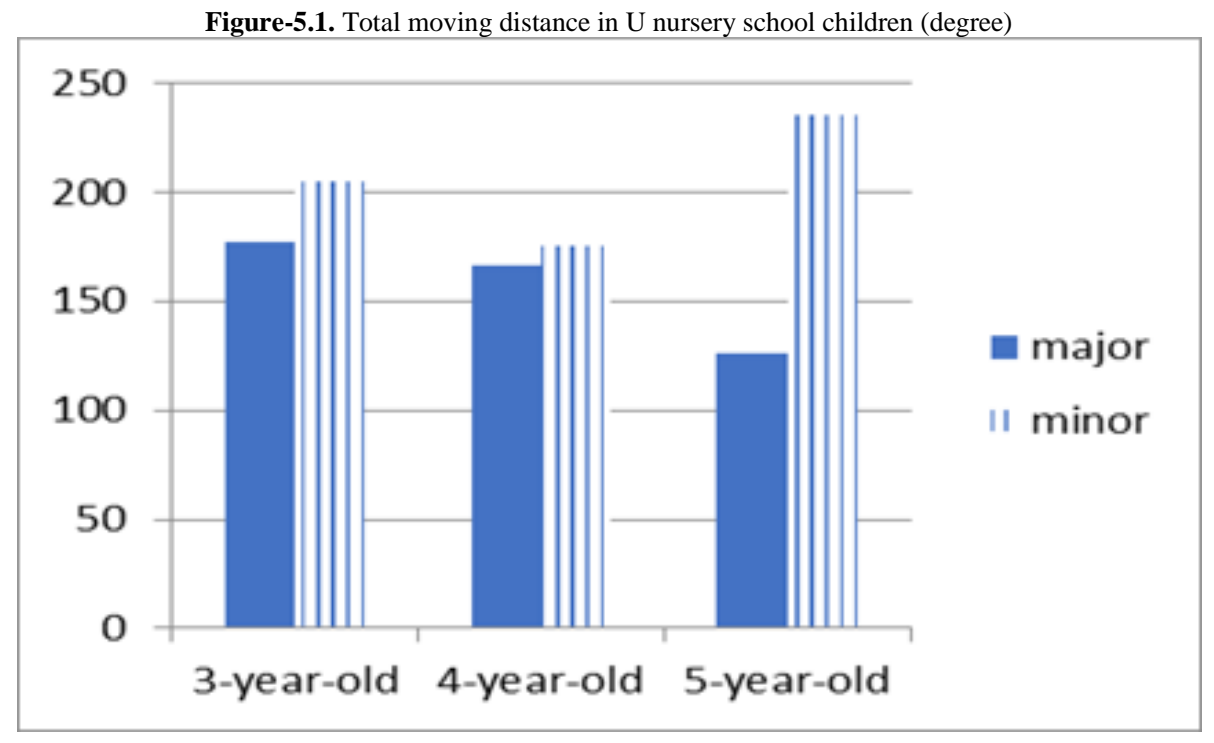

Figure 5.2 shows that in U nursery school, the total moving distance in 5-year-old child is larger for songs in minor key than for songs in major key. 
Figure-5.2. Total moving distance by M nursery school children (degree)

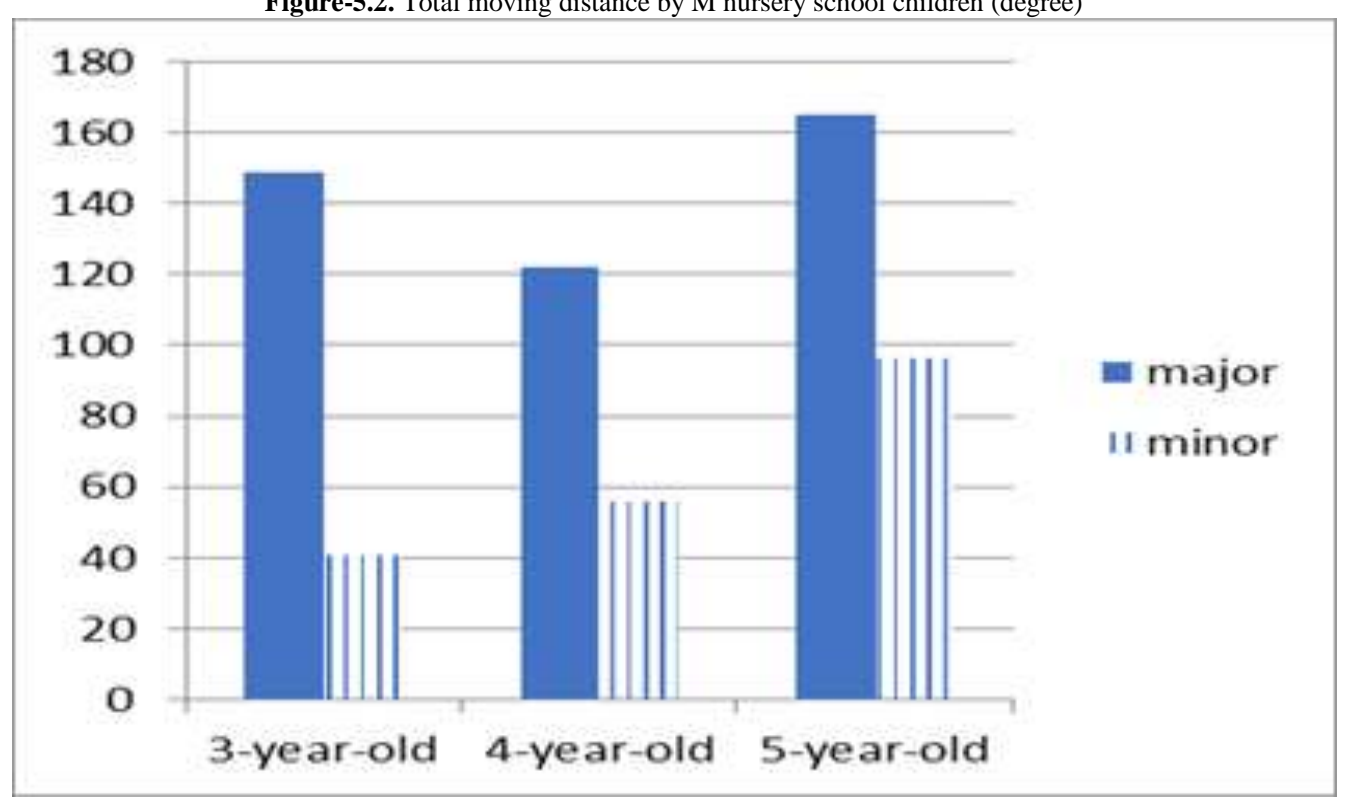

As shown in figure 5.2, the total moving distance by 3-year-olds and 5-year-olds was large in M child facility. At all ages in $\mathrm{M}$ child facility, the total moving distance when singing songs in major key was significantly larger than singing songs in minor key.

Concerning the average data of total moving distance, the author carried out a two-way ANOVA (non-repeated four standards as songs, non-repeated three standards as ages). As the result of a main effect/ interaction of the test, a main effect showed a statistically significant difference (songs: $F(3,104)=10.996, p<.005$ ). As a result of multiple comparisons by Bonferroni method, the total moving distance regarding "Umi" and "Ureshii Hinamaturi" were significantly larger than the data of "Teru teru Bouzu" in 3-year-old. The total moving distance of "Ureshii Hinamaturi" was significantly larger than the data of "Teru teru Bouzu"regarding 4-year-old and 5-year-old.

\subsection{Analysis Results for The First Saccade Occurred During Measurement}

In this section, the author shows a result of the moving average of velocity of the first saccade during measurement in U nursery school and M early childhood facility.

\subsubsection{The Moving Average Velocity of the First Saccade}

Regarding the moving average velocity of the first saccade, the average data of 3-year-old children was significantly larger than that of 4-year-old children in U nursery school. Furthermore, it was found that the moving average velocity when singing a major song was significantly larger than that when singing a minor song in a 3-yearold child at U nursery school and a 5-year-old child at M children's school. It was also found from the difference in the moving average velocity of the first saccade by facility in figures 6.1 and figure 6.2.

Figure-6.1. The moving average velocity (degree / second) of the first saccade in U nursery school

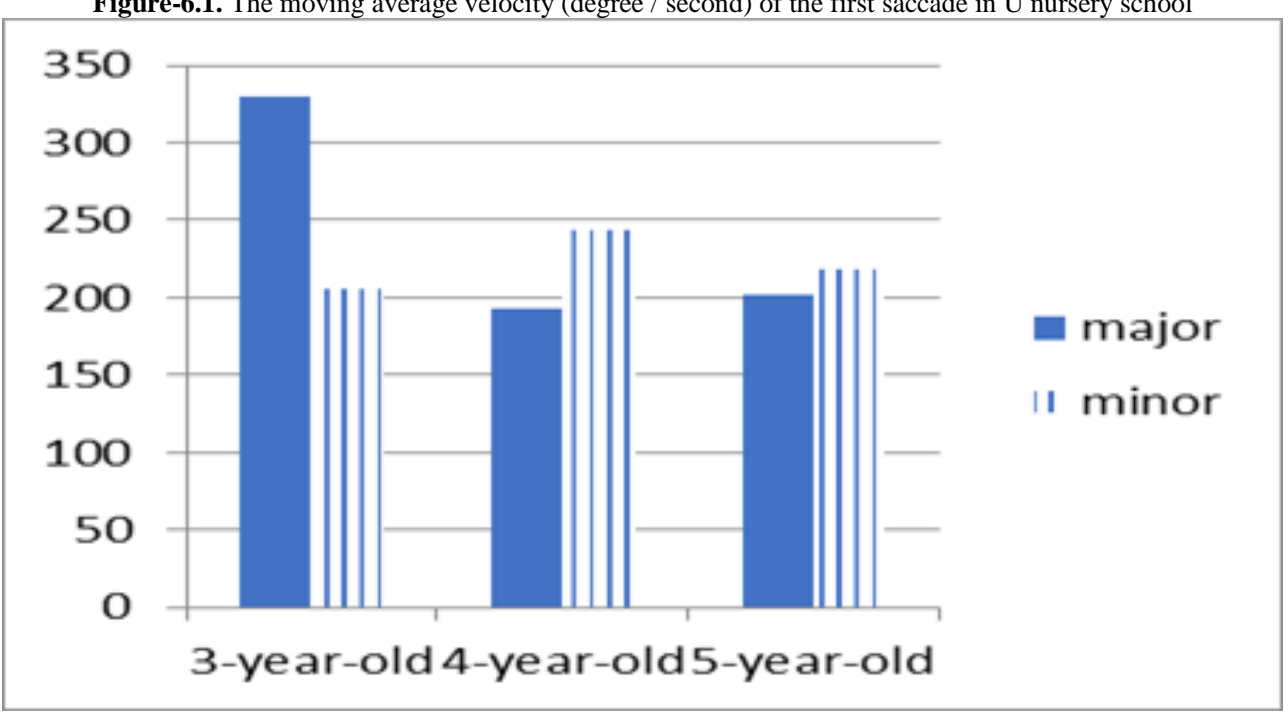


Figure-6.2. The moving average velocity (degree / second) of the first saccade in M nursery school

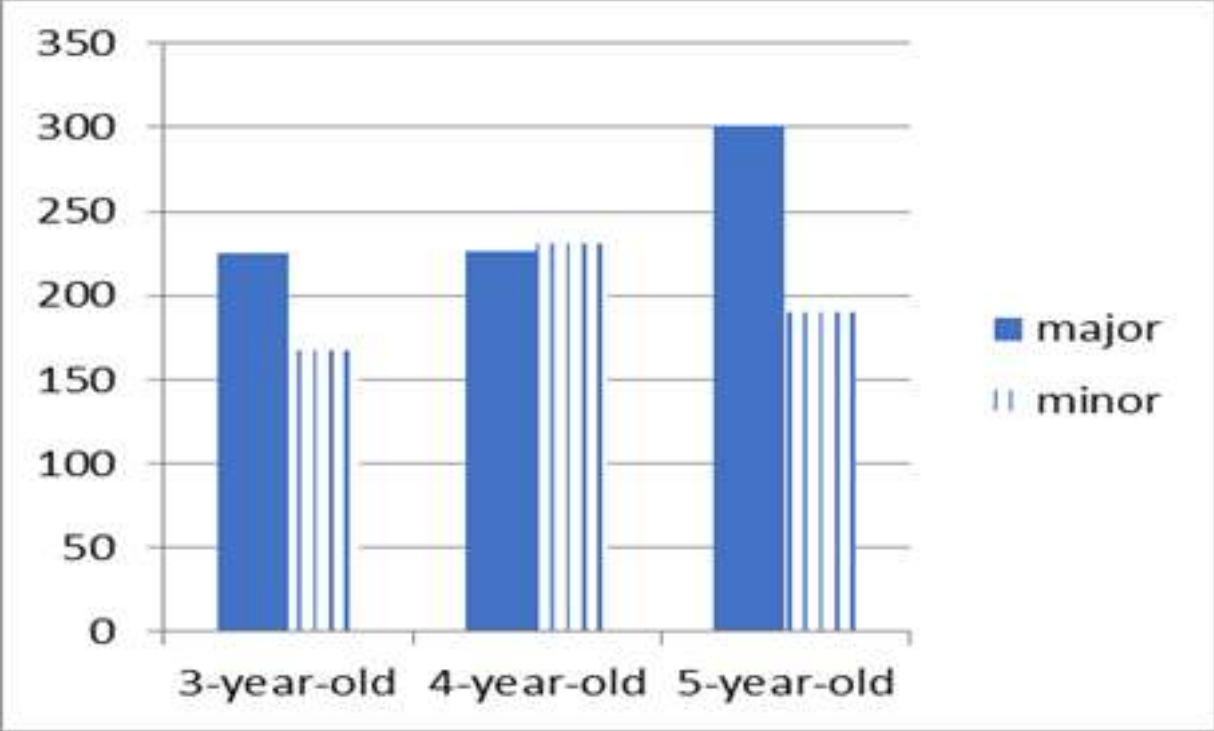

As shown in figure 6.1 and figure 6.2, the moving average velocity of the first saccade of 3-year-old child in $U$ nursery school was 330.1263 degree / second and the moving average velocity of the first saccade of 5-year-old child in M children's school was 300.88 degree / second. Regarding the value of the saccade (the total moving distance) that occurred the first time, the average value of the $M$ child facility was significantly larger than the average value of the $U$ nursery school when singing in the major key in 5-year-old. These characteristics are also clear from the following figures 6.3 and figure 6.4 , which show the first saccade by facility.

Figure-6.3. the first saccade value in U nursery school (degree)
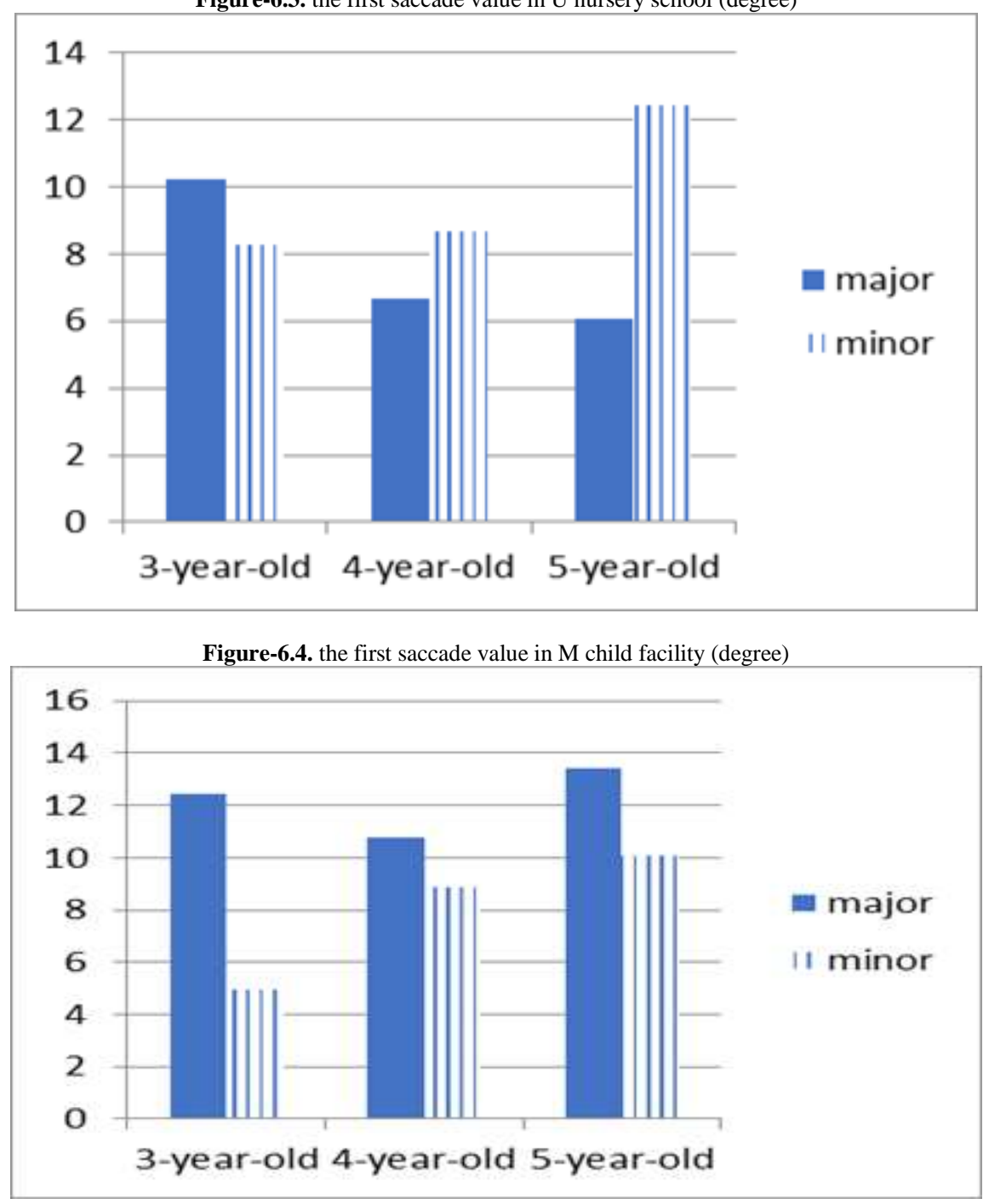
As shown figure 6.3 and figure 6.4, a result of the first saccade value indicated a difference between U nursery school and M early childhood facility. 4-year-old and 5-year-old children in U nursery school showed larger eye movements for songs in minor key than major key although 3-year-old children showed larger eye movements for major key song. The children in U nursery school tended to response Japanese lyric as well as Japanese word. But, the children in $\mathrm{M}$ facility tended to response tonality such as major key or minor key. 3-year-old, 4-year-old, and 5year-old children in $\mathrm{M}$ facility showed larger values of saccade when singing a song in major key than another song in minor key.

\section{Discussion}

In this article, the author used an eye tracker (Tobii Pro Glasses 2) to acquire data on eye movements during musical expression of participant child and to conduct quantitative analysis. A three-way ANOVA was mainly focused on saccade acquired data when singing songs in different major and minor keys by 3-year-olds, 4-year-olds, and 5-year-olds in two early childhood facilities. In general, findings show that significant differences captured in age groups and other factors suggesting change of eye movement based on accumulated experience of music educational influence. In contrast, there were some parameters which were less evident to evaluate as close relationship between eye movements and music experience to be argued for feature quantity for machine learning.

First, when the author is to understand from visual tracking movements examined individually, from heat maps, all the participant children were looking at the appearance of the other child on the front right side and the piano accompaniment on the front left side, and the line-of-sight movement of the U nursery school child was more frequent than that of the $M$ child facility child. Furthermore, $U$ nursery school children tend to look at the piano accompaniment with songs in minor key rather than major key, and participant children in $\mathrm{M}$ child facility looked at both the appearance of other children on the front right side and the piano accompaniment player on the front left side.

Next, based on statistical analysis of a three-way ANOVA based on the facility factor, major / minor factor, and age factor, the acquired data clearly showed a statistically significant difference in the number of occurrences of saccade and the total moving distance. It was found that the number of saccades in U nursery school children was significantly larger than that in $\mathrm{M}$ facility children when singing songs in minor key in all 3-year-old children, 4year-old children, and 5-year-old children. Regarding the total moving distance, 5-year-old children in U nursery school sang a song in minor key was larger than the measurement when singing a song in major key. The total moving distance of 3-year-old children in $\mathrm{M}$ child facility when singing in major key was larger than when singing a song in minor key. These results are considered to depend on the difference in childcare forms between $M$ early childhood facility and U nursery school. M facility takes a childcare form following Montessori method. Children in $\mathrm{M}$ facility have everyday life experiences and musical experiences that are sensitive to the regularity and contrast of various things, so they feel the brightness in the major key of songs and the darkness in the minor key of songs. It can be said that the awareness of the difference due to the tone of the song was reflected in the eye movements during singing. However, U nursery school takes a play-centered childcare form. The children in U nursery school responded to the meaning of the Japanese lyrics rather than the tune, and the spontaneous gestures that accompany the singing become larger. In order to share with other children to minor key of tunes such as "Ureshii Hina Matsuri", it was found that the eye movements for the songs in minor key were also increased in U nursery school.

On the other hand, among the results of researches on adults by Gingras et al. (2015) and Fink et al. (2017), the unchanged pupillary response was the same for children in early childhood obtained in this study by the author. Although an individual difference was observed in the pupil diameter, it changed from $3 \mathrm{~mm}$ to $5 \mathrm{~mm}$, and it was found that no statistically significant difference was observed.

\section{Conclusion}

In this way, the differences of saccade were observed in major / minor and the type of childcare forms when children in early childhood sing by using eye tracker-assisted method for detecting visionary responses. The present investigation provides evidences that music stimuli gives interaction with eye movements. This finding encourages further research with increased number of songs and the number of participant children for songs with various tunes, to asses variety of conditions affecting visual behaviours. Such exploitation of saccades, fixation or any oculomotor movements could be added to feature quantities of 3D motion capture to enhance accuracy of machine learning classification algorhythms which forecasts development degree of sophistication of musical expression.

There is also the challenge of simultaneous analysis with the motion analysis of musical expressions. Regarding research report of the combined use of eye tracker and motion capture, Saakata et al. (2005) quantitatively analyzed the relationship between specific movements of Japanese dance and eye contact, and simultaneous measurement of search step movements and line of sight (Hashimoto and Sato, 2018). Burger et al. (2017), attempted a quantitative analysis of gaze and physical movements that differed according to musical characteristics in a small number of adults. The research point out the need for simultaneous measurement of eye trackers and motion capture, as human musical behavior interacts with gaze and physical movements. Those previous studies are aimed at adults, and there are no research reports on musical expressions of early childhood children so far, so it is necessary to inspect the research method. 


\section{Acknowledgement}

This work was supported by JSPS KAKENHI Grant Number 21K02369.

\section{References}

Ando, A. and Sumikawa, Y. (2012). Development and functional evaluation of teaching materials for observing sawing motion using motion capture and virtual space. Journal of the Japan Society for Educational Technology, 36(2): 103-10. Available: https://doi.org/10.15077/jjet.KJ00008274459

Burger, B. (2013). Move the way you feel: Effects of musical features, perceived emotions, and personality on musicinduced movement. Department of Music, University of Jyväskylä.

Burger, B., Puupponen, A. and Tommi, J., 2017. "Synchronizing eye tracking and optical motion capture:How to bring them together." In Conference on Music \& Eye-Tracking, 2017.Max Planck Institute for Empirical Aesthetics. p. 11.

Burger, B., Puupponen, A. and Jantunen, T. (2018). Syn-chronizing eye tracking and optical motion capture: How to bring them together. Journal of Eye Movement Research, 11(2): 5.

Dahl, S. and Friberg, A. (2007). Visual perception of expressiveness in musicians' body movements. Music Perception, 24: 433-54. Available: https://doi.org/10.1525/mp.2007.24.5.433

Drai-Zerbib, V. and Baccino, T. (2018). Cross-modal music integration in expert memory: Evidence from eyemovements. Journal of Eye Movement Research, 11(2): 4.

Fernandez-Delgado, M., Cernadas, E., Barro, S. and Amorim, D. (2014). Do we need hundreds of classifiers to solve real world classification problems? Journal of Machine Learning Research, 15(90): 3133-81.

Fink, K., Lange, E. and Groner, R. (2019). The application of eye-tracking in music research. Journal of Eye Movement Research, 11(2): 1-4.

Fink, K., Geng, J., Hurley, K. and Janata, P., 2017. "Predicting attention to auditory rhythms using a linear oscillator model and Pupillometry." In Conference on Music and Eye-Tracking.Max Planck Institute for Empirical Aesthetics. p. 13.

Fusase, E. (2017). In "childcare expression technology" music i consideration of specialized skills-line of sight when playing the piano: Through the difference in behavioral proficiency. Nagoya Yanagishiro Junior College Lab Bulletin of Research, (39): 313-31.

Gingras, B., Marin, M., Puig-Waldmüller, E. and Fitch, T. (2015). The eye is listening: Music-induced arousal and individual differences predict pupillary responses. Frontiers in Human Neuroscience: 10. Available: https://doi.org/10.3389/fnhum.2015.00619

Hakuno, Y. and Minagawa, Y. (2017). Effects of tutor's behavior on infants' attention to face and object in the context of joint attention, Studies in sociology, psychology and education. Inquiries Into Humans and Societies, 83: 35-45.

Hashimoto, J. and Sato, S. (2018). Simultaneous measurement of search step movement and line of sight. Journal of Aomori University of Health and Welfare, 18: 29-33. Available: www.info:doi/10.24552/00002128

Higuchi, D., Okumura, U. and Kobayashi, T. (2019). Development of hiragana character sound knowledge for toddlers: Examination using eye tracker (basics of human communication), IEICE technical report. 118(437): 83-88.

Kodama, U., Oba, N. and Ishi, N. (2015). Examination of behavior recognition method in general living environment using machine learning, IEICE technical report. 114(502): 73-78.

Kouroki, M., Matuda, K., Nakamoto, S., Kojima, T., Chou, A. and Kusumi, T. (2016). Effect of eye movement distance on stimulus on preference judgment. Proceedings of the Japanese Society of Cognitive Psychology, 2016(0): 47.

Kusunoki, K., Ozawa, W. and Kanemori, Y. (2017). Basic research on reading difficulty of children with foreign roots: through visual function evaluation and reading ability measurement. Proceedings of the Japan Digital Textbook Society, 6(0): 7-8.

Lörch, L., Fehringer, B. and Münzer, S., 2017. "Reading music. How tonality and notation influence music reading experts' eye movements, pupil dilation and performance in a patternmatching task." In Conference on Music and Eye-Tracking, 2017.Max Planck Institute for Empirical Aesthetics. p. 17.

Marandola, F., 2017. "Eye-Hand synchronisation and interpersonal interaction in xylophone performance: A comparison between African and Western percussionists." In Conference on Music \& Eye-Tracking, 2017. Max Planck Institute for Empirical Aesthetics. p. 18.

Matumoto, A., Mikami, H., Kawamura, H. and Kojima, A. (2014). Examination of form classification method for supporting motor learning of elementary school students who performed motion analysis using image processing and machine learning techniques. Video Information Media Society Technical Report, 38, 51(0): $9-12$.

Moreno-Estevaa, E., White, S., Woodc, J. and Blackc, A. (2019). Application of mathematical and machine learning techniques to analyze eye tracking data enabling better understanding of children's visual cognitive behaviours. Frontline Learning Research, 6(3): 72 - 84. Available: https://doi.org/10.14786/flr.v6i3.365

Mpofu, B. (2016). University students use of computers and mobile devices for learning and their reading speed on different platforms. Universal Journal of Educational Research, 4(4): 926-32. Available: https://doi.org/10.13189/ujer.2016.040430 
Nagai, Y., Hinobayashi, T. and Kesawa, T. (2017). Measurement of joint attention in children with autism spectrum disorders by eye tracker and its clinical usefulness. Special Education Research, 55(4): 201-10.

Neil, M. T., Theodoros, M. and Bampouras, T. D. S. D. (2016). Eye movements affect postural control in young and older females. Frontiers in Aging Neuroscience, 8(216): 1-11.

Plöchl, M. and Obleser, J., 2017. "Do auditory rhythms influence eye movement statistics?" In Conference on Music \& Eye-Tracking, 2017. Max Planck Institute for Empirical Aesthetics. p. 19.

Rajendran (2018). Rajendran, R., Kumar, A., Carter, E., Levin, T., Biswas, G. Predicting learning by analyzing eyegaze data of reading behavior. International Educational Data Mining Society.

Saakata, M., H., M., Yatumura, H., Choku, Y. and Yoshimura, M. (2005). Quantitative analysis of eye contact in Japanese dance: Coincidence counting of line of sight and body movement by eye mark recorder and motion capture. Jinmonkon 2005 Proceedings: 14.

Sano, M. (2019). Predicting developmental degrees of music expression in early childhood by machine learning classifiers with 3D motion captured body movement data. Journal of Educational Research and Reviews, $7(7): 155-68$.

Sano, M. (2020). Verification of a classification prediction method for the development of musical expression in early childhood using a machine learning method based on 3D motion capture data. Advances in Social Sciences Research Journal (International, 7(9): 338 - 58.

Sato, K., Kaiga, T. and Watabe, S. (2010). Utilization of motion capture to support the mastery of dance. Journal of the Japan Society for Educational Technology, 34(Suppl): 133-36. Available: https://doi.org/10.15077/jijet.KJ00007086695

Seong-un, K., Sung-man, L., Eun-ae, K. and Il-ho, Y. (2016). An analysis of eye movement and cognitive load about the editorial design in elementary science textbook. Universal Journal of Educational Research, 4(3): 57075. Available: https://doi.org/10.13189/ujer.2016.040314

Takada, K., Kitasuka, T. and Aritugi, M. (2012). Examination of personal identification method by gait using markerless motion capture device, research report entertainment computingec. 1-7.

Thompson, M. and Luck, G. (2012). Exploring relationships between pianists' body movements, their expressive intentions, and structural elements of the music. Musicae Scientiae, 16: 19-40. Available: https://doi.org/10.1177/1029864911423457

Urakawa, S., Sakai, N., Takamoto, K., Hori, E., Ishikawa, A., Ono, T. and Saijyo, H., 2011. "Infant cognitive development: brain science verifies the importance of eye-to-eye contact." In Proceedings of Tokai Hokuriku Physical Therapy Academic Conference. pp. 4-4.

Watabe, M., Matumura, A. and Uda, N. (2019). An attempt to extract children's tastes from gaze movements and facial expressions in storytelling of picture books. Proceedings of the 81st National Convention, 2019(1): 563-64. 